\title{
Collecting (Bellini) duct carcinoma: A clinical study of a rare fumour and review of the literature
}

\author{
Sebastian Ciszewski, MD; ${ }^{*}$ Artur Jakimów, MD; ${ }^{*}$ Beata Smolska-Ciszewska, MD
}

*Urology Department, Regional Medical Center, Opole, Poland; §Radiotherapy and Chemotherapy Clinic, Maria Skłodowska-Curie Memorial Cancer Center and Institute of Oncology, Gliwice Branch, Poland

Cite as: Can Urol Assoc J 2015;(9-10):E589-93. http://dx.doi.org/10.5489/cuaj.2932

Published online September 9, 2015.

\section{Abstract}

Introduction: We report our 15-year experience of Collecting (Bellini) duct carcinoma (CDC). We retrospectively analyzed patient and tumour characteristics, clinical manifestations, surgical techniques, clinical outcomes, and salvage therapies.

Methods: From January 1999 to December 2013, 1042 patients underwent surgical resection of renal neoplasm. We examined all renal tumors and identified 10 cases $(0.96 \%)$ of CDC.

Results: The study group included 8 men and 2 women, with a median age of 62.5 years. Of these 10 patients, 9 were symptomatic $(90 \%)$. All patients were treated with open nephrectomy. The mean tumour size was $5.7 \mathrm{~cm}$. The pathologic stages were distributed as follows: pT1b in 2 patients (20\%); pT2a in 1 patient $(10 \%)$; pT3a in 3 patients (30\%); and pT3b in 4 patients $(40 \%)$. Grading was assessed according to Fuhrman scale as follows: grade II in 1 patient (10\%); grade III in 3 patients $(30 \%)$; grade IV in 5 patients $(50 \%)$; undetermined grade in 1 patient $(10 \%)$. Four patients $(40 \%)$ relapsed locally. The median time of local recurrence was 4.9 months. Distant metastases occurred in 9 patients (90\%): 4/9 at the time of diagnosis and 5/9 after nephrectomy. The median time of distant metastases after surgery was 8.1 months. Six patients received chemotherapy (gemcitabine plus platinum salts). Radiotherapy was performed in 5 patients. One patient had surgery because of local recurrence and 2 patients were irradiated in the area of the local recurrence. The median overall survival was 7.6 months, and only 2 patients survived more than 2 years after the nephrectomy.

Conclusions: CDCs of the kidney are aggressive and they have a low survival rate. All patients in our study experienced a relapse of their disease. Local recurrence preceded distant metastases. Results of salvage treatments were poor.

\section{Introduction}

Collecting (Bellini) duct carcinoma (CDC) of the kidney is a highly aggressive tumour with an extremely poor prognosis. It is a variety of renal cell carcinoma (RCC) arising from the distal segment of the collecting ducts of Bellini in the renal medulla, accounting for less than $2 \%$ of all renal masses. ${ }^{1-7}$ Mancilla-Jimenez and colleagues ${ }^{8}$ first observed the atypical hyperplastic changes of the adjacent collecting ducts epithelium in 3 out of 34 cases of papillary RCC in 1976. Fleming and Lewi described 6 cases of CDC and presented diagnostic criteria to recognize it as a unique pathological subtype of RCC. ${ }^{9}$ In 1997, the Heidelberg classification of renal tumours identified 5 histologic types of renal cancer: conventional, papillary, chromophobe, collecting duct, and unclassifiable. ${ }^{10}$ According to the International Society of Urological Pathology (ISUP) conference on renal neoplasia in Vancouver in 2013, CDC should include at least some of the lesions from the medullary region, have a predominant formation of tubules, have a desmoplastic stromal reaction, have high-grade cytologic features, have infiltrative growth patterns, have no other typical RCC subtypes or urothelial carcinoma. The consensus at the Vancouver conference was that CDCs are, by definition, high grade and as a consequence should not be assigned a grade. ${ }^{11}$

Of all renal cancers, CDC has the worst prognosis, as most patients develop metastases. Early diagnosis is essential and may increase patient survival. The treatment that yields the longest survival rates is surgery if it is performed in patients with organ-confined small tumours. ${ }^{12}$ Most cases are metastatic at presentation. Several treatment protocols, including chemotherapy, radiotherapy and immunotherapy, have been considered. However, these treatments do not demonstrate a favourable response in most CDC patients.

We report our 15-year experience of CDC in our department. We retrospectively analyzed patient and tumour characteristics, clinical manifestations, surgical technique, clinical outcomes, and salvage therapies. 


\section{Methods}

From January 1999 to December 2013, 1042 patients underwent surgical resection of renal neoplasm in the Urology Department, Regional Medical Center in Opole, Poland a regional tertiary medical referral centre. We examined all renal tumours and identified 10 cases $(0.96 \%)$ of CDC. Diagnosis of CDC was made based on the examination of a nephrectomy specimen. All CDCs were examined by one genitourinary pathologist - the head of Tumour Pathology Department at the centre.

Data were obtained from patient medical records. Prior to the initiation of the treatment, all patients underwent a complete clinical examination and laboratory tests (blood count, liver and renal function tests, coagulation tests). Staging procedures included abdomen and pelvis computed tomography $(\mathrm{CT})$ and chest X-ray or thoracic CT. Clinical and pathological stages were defined according to the 2009 TNM classification system. ${ }^{13}$ Patient performance status was evaluated according to the Eastern Cooperative Oncology Group (ECOG) score. Salvage treatments were also noted.

A statistical analysis was performed using Statistica ver. 7.0 (StatSoft Inc., Tulsa, OK). Overall survival (OS) was evaluated from the date of nephrectomy to the date of the last follow-up visit or death.

\section{Results}

The study group included 8 men (80\%) and 2 women (20\%), with median age of 62.5 years (range: $48-83$ ). Patient performance status as per the ECOG score were: score 0 in 1 patient (10\%); score 1 in 6 patients $(60 \%)$; score 2 in 2 patients (20\%); and score 3 in 1 patient (10\%). Of these 10 patients, 9 were symptomatic $(90 \%)$. The most common clinical symptoms were flank pain $(n=7,70 \%)$, macroscopic hematuria $(n=3,30 \%)$, and weight loss $(n=3$, $30 \%)$. The median time of abdominal or lumbar pain was 3 months (range: $1-7$ ).

On CT, the mean tumour size was $5.7 \mathrm{~cm}$ (range: $3.7-$ 9.7). All tumours had infiltrative growth. Tumours presented with heterogeneous enhancement in 5 cases $(50 \%)$ and cystic component in $4(40 \%)$. At the time of diagnosis, distant metastases were found in 4 patients $(40 \%)$. Metastases were located in lymph nodes $(\mathrm{n}=3,75 \%)$, bone $(\mathrm{n}=3,75 \%)$, liver $(n=2,50 \%)$, and soft tissues $(n=1,25 \%)$.

All patients were treated with open nephrectomy, using the transperitoneal approach. There were no postoperative complications and the median time of hospitalization was 10 days (range: 8-14). At least one of the surgeons was a urologist and/or FEBU (Fellow of the European Board of Urology) specialist.

On pathologic examinations, the mean tumour size was $7.3 \mathrm{~cm}$ (range: 3.0-11.0). The pathologic stages were distrib- uted as follows: pT1b in 2 patients (20\%); pT2a in 1 patient $(10 \%)$; pT3a in 3 patients $(30 \%)$; and pT3b in 4 patients (40\%). All postoperative margins were negative. Despite Vancouver conference's suggestion of not assigning a CDC grade, we graded patients based on the Fuhrman scale. All CDCs were examined before publication of conference recommendations: grade II in 1 patient $(10 \%)$; grade III in 3 patients (30\%); grade IV in 5 patients $(50 \%)$; undetermined grade in 1 patient $(10 \%)$. Eight patients $(80 \%)$ had solitary tumours. Additional CDCs were identified in the examined kidneys in 2 cases ( 3 tumours), with mean size of $0.8 \mathrm{~cm}$ (range: 0.5-1.5) (Table 1).

After nephrectomy, all patients were referred to the oncology centre. Patients were evaluated every 3 months or depending on clinical symptoms. Four patients (40\%) relapsed locally. The median time of local recurrence was 4.9 months (range: 1.6-10.0). One patient underwent surgery due to local recurrence with cytoreductive intent. He was young, in good performance status, and recurrence occurred 10 months after nephrectomy with no evidence of distant metastases. Unfortunately, surgical treatment was not radical and distant metastases occurred 2 months after salvage surgical treatment. Two patients were irradiated in the area of the local recurrence. Gastrointestinal symptoms (nausea, vomiting, abdominal pain) occurred during radiotherapy.

Distant metastases occurred in 9 patients (90\%): 4/9 at the time of diagnosis and 5/9 after nephrectomy. The median time of distant metastases after surgery was 8.1 months (range: 1.6-15.1). Metastases were located in the lymph nodes $(n=6,67 \%)$, liver $(n=5,56 \%)$, bone $(n=4,44 \%)$, lung $(n=3,33 \%)$, contralateral kidney $(n=2,22 \%)$, brain $(n=1,11 \%)$, suprarenal $(n=1,11 \%)$, spermatic cord $(n=1$, $11 \%)$, soft tissues $(n=1,11 \%)$, and mesentery $(n=1,11 \%)$. Two patients underwent surgery due to distant metastases (liver, spermatic cord). Three patients were irradiated in the area of painful bone metastases.

Six patients received two-6 (median 5) cycles of chemotherapy, according to gemcitabine and platinum salts scheme (GC). Because of disease progression during GC (2 patients) or nephrotoxicity (1 patient), the chemotherapeutic scheme was changed to doxorubicin or docetaxel. Only 1 patient had partial response, others progressed after therapy. The duration of remission was 5 months. Nausea, vomiting, fatigue, myelosupression, and renal toxicity occurred during GC chemotherapy (Table 2).

The median follow-up was 7.2 months (range: 0.5-22.6). One patient was lost to follow-up, and the remaining patients died because of disease progression. The median OS was 7.6 months (range: 1.5-24.3). Only 2 patients survived more than 2 years after nephrectomy. 


\begin{tabular}{|c|c|}
\hline Characteristics & $\begin{array}{l}\text { Study group } \\
(\mathrm{N}=10)\end{array}$ \\
\hline \multicolumn{2}{|l|}{ Age, years } \\
\hline Median & 62.5 \\
\hline Range & $48-83$ \\
\hline \multicolumn{2}{|l|}{ Sex } \\
\hline Female & $2(20 \%)$ \\
\hline Male & $8(80 \%)$ \\
\hline \multicolumn{2}{|l|}{ ECOG score } \\
\hline 0 & $1(10 \%)$ \\
\hline 1 & $6(60 \%)$ \\
\hline 2 & $2(20 \%)$ \\
\hline 3 & $1(10 \%)$ \\
\hline \multicolumn{2}{|l|}{ Symptoms } \\
\hline Yes & $9(90 \%)$ \\
\hline No & $1(10 \%)$ \\
\hline \multicolumn{2}{|l|}{ Symptoms } \\
\hline Flank pain & $7(70 \%)$ \\
\hline Hematuria & $3(30 \%)$ \\
\hline Weight loss & $3(30 \%)$ \\
\hline \multicolumn{2}{|c|}{$\mathrm{CT}$ tumour size (maximum diameter), $\mathrm{cm}$} \\
\hline Median & 5.7 \\
\hline Range & $3.7-9.7$ \\
\hline \multicolumn{2}{|c|}{ Primary tumour pathologic stage } \\
\hline pT1b & $2(20 \%)$ \\
\hline pT2a & $1(10 \%)$ \\
\hline pT3a & $3(30 \%)$ \\
\hline pT3b & $4(40 \%)$ \\
\hline \multicolumn{2}{|l|}{ TNM stage } \\
\hline I & $2(20 \%)$ \\
\hline II & $1(10 \%)$ \\
\hline III & $3(30 \%)$ \\
\hline IV & $4(40 \%)$ \\
\hline \multicolumn{2}{|c|}{$\begin{array}{l}\text { Pathologic examination's tumour size } \\
\text { (maximum diameter), } \mathrm{cm}\end{array}$} \\
\hline Median & 7.3 \\
\hline Range & $3.0-11.0$ \\
\hline \multicolumn{2}{|l|}{ Fuhrman grade } \\
\hline II & $1(10 \%)$ \\
\hline III & $3(30 \%)$ \\
\hline IV & $5(50 \%)$ \\
\hline Undetermined & $1(10 \%)$ \\
\hline Presence of distan & $4(40 \%)$ \\
\hline At diagnosis & $5(50 \%)$ \\
\hline After nephrectom & \\
\hline \multicolumn{2}{|c|}{ Location of distant metastases } \\
\hline Lymph nodes & $6(67 \%)$ \\
\hline Liver & $5(56 \%)$ \\
\hline Bone & $4(44 \%)$ \\
\hline Lung & $3(33 \%)$ \\
\hline Kidney & $2(22 \%)$ \\
\hline Brain & $1(11 \%)$ \\
\hline Suprarenal & $1(11 \%)$ \\
\hline Spermatic cord & $1(11 \%)$ \\
\hline Soft tissue & $1(11 \%)$ \\
\hline Mesentery & $1(11 \%)$ \\
\hline
\end{tabular}

\section{Discussion}

Except for a few studies published in recent years, ${ }^{1-7}$ only isolated cases have been reported. The American series by Wright based on the Surveillance, Epidemiology and End Results (SEER) database characterized CDC epidemiology in North America in comparison to clear cell carcinoma. In this study, CDC was listed as more common in African American $(23 \%)$ and males $(70 \%)$. The median patient age was listed as 63. At diagnosis, CDC was also more commonly locally advanced $(33 \%)$, metastatic $(28 \%)$, and poorly differentiated $(70 \%)$, resulting in worse 1 - and 3-year disease-specific survivals $(70 \%$ and $58 \%$, respectively) in comparison to clear cell carcinoma. ${ }^{1}$ The European ${ }^{3}$ and Japanese ${ }^{5}$ studies also found that CDC presents at an advanced stage and has a poor prognosis. As in Wright study, males predominated $(70 \%)$ and the mode of presentation was classified as symptomatic in about $70 \%$ of patients. Common clinical symptoms of CDC include painless gross hematuria, lumbar and/ or abdominal pain, waist and abdominal mass, fatigue, fever, and weight loss. Additionally, these series indicated that most patients with CDC exhibit loco-regional or systemic disease at presentation. The most common metastatic sites included regional lymph nodes, lungs, and bone. ${ }^{5}$

We noted similar patient and tumour characteristics: median age 62.5 years, male predominance $(80 \%)$, presence of clinical symptoms $(90 \%)$, pathological stage T3+ $(70 \%)$, high Fuhrman grades III and IV $(80 \%)$, and distant metastases at presentation (40\%).

May and colleagues assessed the prognostic parameters for CDC-specific mortality. They analyzed clinical and pathological data on 95 patients with CDC. The following factors independently predicted disease-specific mortality: American Society of Anesthesiologists (ASA) score was 3-4, tumour size greater than $7 \mathrm{~cm}$, stage M1, Fuhrman grade $3-4$, and lymphovascular invasion. The risk score was generated using the results of the multivariable regression model and gave a sum score of 0 to 7 . Based on these parameters, patients were divided into low (0-2 points), intermediate (3 points), and high risk (4-7 points) groups, with a 5-year disease-specific survival rate of $96 \%, 62 \%$ and $8 \%$, respectively $(p<0.001) .^{3}$

Imaging examinations (ultrasound examination, CT or magnetic resonance imaging $[\mathrm{MRI}]$ ) are the main ways to diagnose CDC. Solitary tumours, medullar location, weak and heterogeneous enhancement, involvement of the renal sinus, infiltrative growth, preserved renal contour, calcifications, and a cystic component are common CT findings in patients with CDC of the kidney. CT findings are nonspecific and do not allow CDC to be easily differentiated from the other subtypes of RCC, ${ }^{14,15}$ such as renal medullary carcinoma, sarcomatoid renal cell carcinoma, and renal pelvis carcinoma, so its diagnosis requires pathological 


\begin{tabular}{|c|c|c|c|c|c|c|c|c|c|c|c|}
\hline No & Age & Sex & $\begin{array}{l}\text { ECOG } \\
\text { score }\end{array}$ & pT & $\begin{array}{l}\text { Tumour } \\
\text { size, } \mathbf{~ c m}\end{array}$ & LR & $\begin{array}{l}\text { Time to LR, } \\
\text { months }\end{array}$ & DM & $\begin{array}{l}\text { Time to DM, } \\
\text { months }\end{array}$ & Salvage treatment & $\begin{array}{c}\text { OS, } \\
\text { months }\end{array}$ \\
\hline 1 & 48 & M & 0 & pT1b & 6.0 & + & 10.0 & + & 12.4 & $\begin{array}{l}\text { LR-Surgery, DM-CHT: } \\
\text { 3xGC, PD, 3xdocetaxI }\end{array}$ & $21.5 \mathrm{DD}$ \\
\hline 2 & 55 & M & 1 & рТЗа & 7.5 & - & & + & BN & RT-bones & $3 \mathrm{DD}$ \\
\hline 3 & 76 & M & 1 & рT3b & 6.0 & - & & + & 15.1 & CHT: 5xGC, PD & 24.2 DD \\
\hline 4 & 62 & M & 1 & pT3b & 6.0 & - & & + & 8.1 & $\begin{array}{l}\text { Surgery - spermatic } \\
\text { cord }\end{array}$ & Lost to FU \\
\hline 5 & 61 & M & 1 & pT3b & 10.0 & + & 7.9 & - & & $\begin{array}{l}\text { RT (30Gy), SD } \\
\text { (4 months), PD, } \\
\text { CHT: } 2 x G C, P D \\
2 \text { xdoxorubicin }\end{array}$ & $21.2 \mathrm{DD}$ \\
\hline 6 & 63 & M & 2 & pT3b & 8.0 & - & & + & BN & $\begin{array}{l}\text { RT-bones, CHT:2xGC, } \\
\text { renal toxicity, } \\
\text { 1xDoxorubicin }\end{array}$ & 7.2 DD \\
\hline 7 & 60 & $\mathrm{~F}$ & 1 & pT1b & 6.0 & + & 1.9 & + & 7.9 & $\begin{array}{l}\text { LR-RT (50Gy), PR (3 } \\
\text { months), DM, CHT:6xGC } \\
\text {, PR (5 months), PD, } \\
\text { Surgery (liver) }\end{array}$ & 24.3 DD \\
\hline 8 & 83 & M & 2 & рT3а & 11.0 & - & & + & BN & - & 1.5 DD \\
\hline 9 & 64 & $\mathrm{M}$ & 1 & pT2a & 9.0 & + & 1.6 & + & 1.6 & - & $2.0 \mathrm{DD}$ \\
\hline 10 & 73 & $\mathrm{~F}$ & 3 & pT3a & 3.0 & - & & + & BN & $\begin{array}{c}\text { RT-bones (BN), } \\
\text { CHT:3xGC }\end{array}$ & 4.2 DD \\
\hline
\end{tabular}

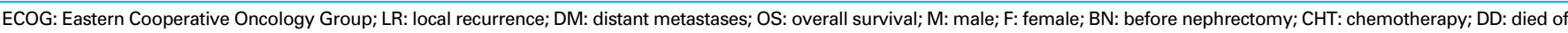
disease; FU: follow-up; GC: platinum salts+gemcitabine; PD: progressive disease; PR: partial response; RT: radiotherapy; SD: stable disease.

examination. Also MRI results are not specific. Zhu and colleagues found that the MRI revealed cystic components, poorly defined tumour, isointense tumour on T1-weighted imaging and iso- or hypointense on T2-weighted imaging; the MRI also demonstrated lower enhancement within the tumour than the renal cortex and medulla. ${ }^{15}$

Most CDC patients undergo surgery (nephrectomy, nephron-sparing surgery), and only in a few cases have diagnostic renal mass biopsies been performed. ${ }^{1,5,6}$ Percutaneous renal mass biopsy is an option to obtain histology and to select the most suitable form of treatment in metastatic disease. Clinical data about role of cytoreductive nephrectomy in CDC are scarce. In 2003 Mejean and colleagues concluded that renal mass biopsy should be performed first when radiological finding suggest CDC, because 3 of 10 patients in their series died during perioperative period. ${ }^{16}$ Conversely, Abern and colleagues in 2012 examined 227 cases of CDC from the SEER database and revealed that patients selected for cytoreductive surgery had improved survival. ${ }^{2}$

Cytoreductive nephrectomy was performed in all patients in our study, even in those with disseminated disease or in poor performance status. One patient also underwent surgery due to local recurrence 10 months after nephrectomy. He was young, in good performance status with no evidence of distant metastases.

Our study has its limitations, including its retrospective nature. All patients revealed disease relapses. Local recurrences preceded distant metastases. The median time of local recurrence and distant metastases after nephrectomy was 4.9 and 8.1 months, respectively.

Attempts at controlling the disease with immunotherapy, targeted therapy or aggressive chemotherapy have met with very limited success. Chemotherapy for urothelial cancer is usually used because CDC has a mesonephric origin. ${ }^{6}$ The largest prospective study consisted of 23 cases treated with the GC scheme. Oudard and colleagues demonstrated the effectiveness of a GC regimen in inducing a $26 \%$ objective response rate in metastatic CDC. ${ }^{6}$ Given the lack of any other beneficial agent, a GC regimen should be considered the standard of care for first-line systemic treatment of metastatic CDC. ${ }^{17}$ Barrascout and colleagues presented a case report of complete remission of pulmonary metastases and long-term survival in patients treated with cisplatin, gemcitabine, and bevacizumab. ${ }^{18}$

Six of our patients received chemotherapy GC, but all of them, except 1, progressed during or just after treatment. One patient had partial regression, with 5 months of remission. The radiotherapy was also performed with short pain relief.

Tokuda and colleagues studied 34 patients treated with immunotherapy (interferon- $\alpha$, interferon- $\gamma$, interleukin-2) and found no response. ${ }^{3}$ Also Motzer and colleagues presented 15 patients with CDC treated with immunotherapy also with no effect. ${ }^{7}$ Procopio and colleagues assessed 13 patients with $C D C$ receiving targeted therapies and 3 patients experienced periods of disease stabilization. ${ }^{19}$ Miyake and 
colleagues ${ }^{20}$ and Chua and colleagues ${ }^{21}$ presented case reports of partial response of metastatic CDC after sunitinib therapy. Ansari and colleagues reported a response, with minimal side effects, to sorafenib in a patient with metastatic CDC. ${ }^{22}$ Dason's review also indicated that immunotherapy is not effective in treating metastatic $\mathrm{CDC}$, also there was no evidence to support the efficacy of targeted therapy, such as sunitinib or sorafenib, beyond small series or case reports. ${ }^{17}$

\section{Conclusions}

CDCs of the kidney are aggressive and they have a low survival rate. All patients in our study experienced a relapse of their disease. Local recurrence preceded distant metastases. Results of salvage treatments were poor.

Competing interests: The authors all declare no competing financial or personal interests.

This paper has been peer-reviewed.

\section{References}

1. Wright JL, Risk MC, Hotaling J, et al. Effect of collecting duct histology on renal cell cancer outcome. J Urol 2009;182:2595-9. http://dx.doi.org/10.1016/i.juro.2009.08.049

2. Abern MR, Tsivian $M$, Polascik TJ, et al. Characteristics and outcomes of tumors arising from the distal nephron. Urology 2012;80:140-6. http://dx.doi.org/10.1016/i.urology.2012.03.034

3. Karakiewicz PI, Trinh QD, Rioux-Leclercq N, et al. Collecting duct renal cell carcinoma: A matched analysis of 41 cases. Eur Urol 2007;52:1140-5. http://dx.doi.org/10.1016/i.eururo.2007.01.070

4. May M, Ficarra V, Shariat SF, et al. Impact of clinical and histopathological parameters on disease specific survival in patients with collecting duct renal cell carcinoma: Development of a disease specific risk model. J Urol 2013;90:458-63. http://dx.doi.org/10.1016/i.juro.2013.02.035

5. Tokuda N, Naito S, Matsuzaki 0 , et al. Collecting duct (Bellini duct) renal cell carcinoma: A nation-wide survey in Japan. Japanese Society of Renal Cancer. J Urol 2006;176:40-3. http://dx.doi.org/10.1016/ S0022-5347(06)00502-7

6. Oudard S, Banu E, Vieillefond A, et al. Prospective multi-center phase II study of gemcitabine plus platinum salt for metastatic collecting duct carcinoma: Results of a GETUG (Groupe d'Etudes des Tumeurs Uro-Genitales) study. J Urol 2007;177:1698-702. http://dx.doi.org/10.1016/i.juro.2007.01.063
7. Motzer RJ, Bacik J, Mariani T, et al. Treatment outcome and survival associated with metastatic renal cell carcinoma of non-clear-cell histology. J Clin Oncol 2002;20:2376-81. http://dx.doi.org/10.1200/ JC0.2002.11.123

8. Mancilla--jimenez R, Stanley RJ, et al. Papillary renal cell carcinoma: A clinical, radiologic, and pathologic study of 34 cases. Cancer 1976;38:2469-80.

9. http://dx.doi.org/10.1002/1097-0142(197612)38:6<2469::AID-CNCR2820380636>3.0.C0;2-R

10. Fleming S, Lewi HJ. Collecting duct carcinoma of the kidney. Histopathology 1986;10:1131. http:// dx.doi.org/10.1111/i.1365-2559.1986.tb02553.x

11. Kovacs $G$, Akhtar $M$, Beckwith $B J$, et al. The Heidelberg classification of renal cell tumours. J Path 1997;183:131-3. http://dx.doi.org/10.1002/(SICI) 1096-9896(199710) 183:2<131::AIDPATH931>3.0.CO;2-6

12. Srigley JR,Delahunt B, Eble JN, et al. The International Society of Urological Pathology (ISUP) Vancouver Classification of Renal Neoplasia. Am I Surg Pathol 2013;37:1469-89. http://dx.doi.org/10.1097/ PAS.0b013e318299f2dl

13. Gupta R, Billis A, Shah RB, Moch H, et al. Carcinoma of the collecting ducts of bellini and renal medullary carcinoma: Clinicopathologic analysis of 52 cases of rare aggressive subtypes of renal cell carcinoma with a focus on their interrelationship. Am I Surg Pathol 2012;36:1265-78. http://dx.doi.org/10.1097/ PAS.0b013e3182635954

14. Edge SB et al. AJCC Cancer Staging Handbook. 7th ed. New York, NY: Springer; 2010;525-38.

15. Yoon SK, Nam KJ, Rha SH, et al. Collecting duct carcinoma of the kidney: CT and pathologic correlation. Eur J Radiol 2006;57:453-60. http://dx.doi.org/10.1016/i.eirad.2005.09.009

16. Zhu Q, Wu J, Wang Z, et al. The MSCT and MRI findings of collecting duct carcinoma. Clin Radiol 2013;68:1002-7. http://dx.doi.org/10.1016/i.crad.2013.04.004

17. Mejean $A$, Roupret $M$, Larousserie $F$, et al. Is there a place for radical nephrectomy in the presence of metastatic collecting duct (Bellini) carcinoma? J Urol 2003;169:1287-90. http://dx.doi.org/10.1097/01. ju.0000050221.51509.f5

18. Dason S, Allard C, Sheridan-Jonah A, et al. Management of renal collecting duct carcinoma: A systematic review and the McMaster experience. Curr Oncol 2013;20:223-32. http://dx.doi.org/10.3747/ co.20.1230

19. Barrascout E, Beuselinck B, Ayllon J, et al. Complete remission of pulmonary metastases of Bellini duct carcinoma with cisplatin, gemcitabine and bevacizumab. Am J Case Rep 2012;13:1-2. http://dx.doi. org/10.12659/AJCR.882234

20. Procopio G, Testa I, lacovelli $R$, et al. Treatment of collecting duct carcinoma: Current status and future perspectives. Anticancer Res 2014;34:1027-30.

21. Miyake H, Haraguchi T, Takenaka A, et al. Metastatic collecting duct carcinoma of the kidney responded to sunitinib. Int I Clin Oncol 2011;16:153-5. http://dx.doi.org/10.1007/s10147-010-0116-z

22. Chua $M E$, Olondriz $K$, Maniwa $M$, et al. Collecting duct of bellini renal carcinoma with psoas muscle recurrence: A case report and review of literature. Can Urol Assoc J 2014;8:e167-71. http://dx.doi. org/10.5489/cuaj.1603

23. Ansari J, Fatima A, Chaudhri S, et al. Sorafenib induces therapeutic response in a patient with metastatic collecting duct carcinoma of kidney. Onkologie 2009;32:44-6. http://dx.doi.org/10.1159/000183736

Correspondence: Dr. Sebastian Ciszewski, Urology Department, Regional Medical Center, Opole, Poland; s_ciszewski@op.pl 